\title{
Case Report: Investigating the Effect of Organizational Silence and Voice on Employees' Performance Based on the Mediating Role of Ethical Leadership: A Case Study of Tehran Metropolitan Fire Station
}

\author{
Mohammad Mehdi Parhizgar $^{1 *}$ (D), Matineh Moghaddam² ${ }^{\text {, Tohid Alizadeh Hossein Hajlou }}{ }^{1}$, Reza Norouzi Ajirloo ${ }^{3}$
}

1. Business Management, Commercial Policy Orientation, Graduate Center, Payame Noor University, Tehran, Iran.

2. Business Administration, Commercial Policy Orientation, Graduate Center, Payame Noor University, Tehran, Iran.

3. Industrial Management, Payame Noor University, Tehran, Iran.

\begin{tabular}{|c|c|}
\hline $\begin{array}{l}\text { Use your device to scan } \\
\text { and read the article online }\end{array}$ & Citation: Parhizgar MM, Moghaddam M, Alizadeh Hossein Hajlou T, Norouzi Ajirloo R. Investigating the Effect of Organization- \\
\hline 口is: & $\begin{array}{l}\text { al Silence and Voice on Employees' Performance Based on the Mediating Role of Ethical Leadership:A Case Study of Tehran Met- } \\
\text { ropolitan Fire Station. Health in Emergencies and Disasters Quarterly. 2019; 4(4):229-236. http://dx.doi.org/10.32598/hdq.4.4.229 }\end{array}$ \\
\hline 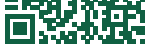 & dol: http://dx.doi.org/10.32598/hdq.4.4.229 \\
\hline
\end{tabular}

\section{(c) (i) (\$)}

Article info:

Received: 13 Dec 2018

Accepted: 10 Apr 2019

Available Online: 01 Jul 2019

Keywords:

Organizational voice health, Ethical leadership, Human relief

\section{A B STRACT}

Background: The lack of expressing opinions of employees working in organizations can cause a phenomenon called organizational silence. Organizational silence has a damaging effect on employee's productivity. The organizational sound and silence about organizational performance are currently one of the fundamental organizational challenges.

Materials and Methods: In this descriptive, correlational study, regression analysis was used to analyze the relationship between the studied factors. Using the Morgan table and stratified random sampling method, 317 subjects were selected and assessed by the structural equation modeling (SEM) with SmartPLS software.

Results: The results showed a significant relationship between organizational silence and performance with a path coefficient of 0.179 and a significant difference of 3.289. Also, there was a significant relationship between organizational voice and performance with a path coefficient of 0.393 and a significant level of 6.766. Besides, a significant relationship existed between organizational voice and ethical leadership with a path coefficient of 0.247 and a significance level of 3.883, and finally, between the focal variables (silence and organizational voice) and organizational performance with moral leadership with a path coefficient of 0.315 and a significance of 5,485. Accordingly, the results indicated the suitability of the model.

Conclusion: The results showed a significant relationship between organizational sound and silence and employee's performance, considering the mediating role of moral leadership in the organization. It can be concluded that one of the essential tasks of firefighters and firefighting leaders and managers is to identify and break the climate of silence and motivate the employees to talk in their workplace for subsequently improving their performances.

\footnotetext{
* Corresponding Author:

Mohammad Mehdi Parhizgar, PhD.

Address: Business Management, Commercial Policy Orientation, Graduate Center, Payame Noor University, Tehran, Iran.

E-mail: m.parhizgar@pnu.ac.ir
} 


\section{Introduction}

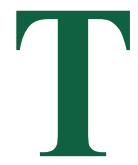

oday, due to the increased competition among organizations, customers with high expectations, and a high focus on quality, organizations expect more from their employees and want them to take the initiative, express opinions, and accept responsibility. To survive, organizations need employees who are responsive to the environmental challenges, eager to acquire knowledge, and defend their organizational beliefs. In other words, the employees' failure to express opinions in an organization can cause a phenomenon called organizational silence [1]. Since employees' silence is closely linked to their creativity, decision making, effectiveness, and mood, identifying the factors that influence them and their impact on employee's performance are important. Some organizations are unaware of these factors [2]. They know that silence has become a powerful force in organizations, but no in-depth research has yet been conducted on its effects [3].

Organizational silence can have a devastating impact on the employee's performance. Many employees blame organizations as the main culprit in the failure of management plans. They consider the organization as a major barrier to change plans because there is no communication and information support in the system. When a system fosters a climate of silence, different views, beliefs, preferences, and organizational goals will discourage the staff from expressing their ideas. Therefore, such a system can enter into a process that will neither achieve its goals properly nor try to learn from experiences. Organizational silence is a social phenomenon that occurs at the organizational level and affects many organizational characteristics [4].

These organizational characteristics include efficiency, performance, decision making, management processes, culture, and employees' perceptions of the factors affecting silent. Although silence is widely observed in organizations, researchers ignore it, even when silence is acknowledged [5]. In the traditional conceptualization, silence is defined as a passive behavior that not only is opposite to the voice but also affects one's behavior [6]. Silence is defined as the absence of sound in its own form, which includes cognition, feelings, or statements, such as disagreement or confirmation [7]. Acaray and Akturan examined the Ralationship between Organizational Cittizenship Behaviour and Organizational Silence. They found out that acquiescent silence and defensive silence had a negative effect on organi- zational citizenship behavior, whereas prosocial silence had a positive effect on it [8].

Van Dyne et al. expanded the dimensions of organizational silence presented by Pinder and Harlos and suggested that the employees' silence may also be due to prosocial motivations. According to them, the prosocial silence refers to the denial of beliefs and information related to the work issues, to benefit other individuals or organizations, which affects the performance of the organization [9]. In the study of Amani et al., the statistical society was included all the Yazd University employees (425 people) in 1393 that 100 people were selected randomly based on Cochran's formula. The results showed that organizational silence have positive and significant relationship with organizational agility [10].

Van Dyne et al. and other scholars similarly defined the term "organizational voice" as the active behavior of employees to change the status quo of the organization [2, $7,9,11,12]$, while it may require a process that enhances justice and facilitates the status quo of the employee $[13,14]$. In a study on employees' perceptions of independence and its impact on their performance at work, challenges, and failure to express opinions and concerns of 586 nurses in the workplace and its impact on their performance was investigated. The results showed that the relationship between individual performance control and employee voice is u-shaped. Employees with stronger identities have less voice and expression when individual performance control is low [11]

Organizational leadership is the most crucial factor in sustaining the life and success of an organization and plays a vital role in the growth, development, and progress of the organization. The leadership and management of an organization and also finding success in performing duties and responsibilities require knowledge, skill, and moral responsibility [15]. Success in an organization can be caused by creating and applying ethical leadership. Ethical leadership has received considerable attention during the early years of the third millennium as it creates a healthy workplace, resulting from its organizational, group and individual outcomes. All organizations, directly or indirectly, benefit from ethical behavior and must strive to develop ethical standards in their workplaces and also make the right decisions. The first step in promoting ethical standards in organizations is to implement ethical management and leadership in an organization $[16,17]$ (Fifure $1 \&$ Figure 2).

The leader's behavior has a significant impact on employees' performance. A study examined the relationship 
between transformational leadership and employee performance outcomes and found a positive relationship between them [18]. Besides, ethical leadership can have a more significant impact on the employees by using influential and charismatic leaders and its consequent impact on organizational performance.

Given the importance of human resource performance and also the impact of organizational silence and voice, this study aimed at evaluating the effect of ethical leadership (as a mediator of the relationship between organizational silence and organizational voice) on employees' performance. We examined whether the relationship between organizational silence and organizational voice affects the performance of employees.

\section{Materials and Methods}

In this descriptive study, 317 employees working in the fire departments (firefighters) in Tehran City, Iran, were recruited using Krejcie \& Morgan Table and Stratified random sampling technique. For collecting data, four following scales were used in Persian: a. ethical leadership with three dimensions of morality and fairness, role clarification, and power-sharing [14]; b. organizational silence with three dimensions of acquiescent silence, defensive silence, and prosocial silence [7]; c. organizational voice with three dimensions of acquiescentvoice, opposing voice, and prosocial voice [9]; and d. employee performance [8]. The items are rated on a 5-point Likert scale from 1 (strongly disagree) to 5 (strongly agree). The obtained data were analyzed in SPSS and SmartPLS3 software using the Pearson correlation test, regression analysis, and Structural Equation Modeling (SEM).

\section{Results}

For testing normal distribution of data, skewness and kurtosis of data were measured. The results are shown in Table 1 and indicate the data had a normal distribution. For a normal distribution, skewness should be between -3 and +3 , and kurtosis less than 7 . In this regard, the Pearson correlation test was used for testing the association between latent variables. The results are presented in Table 2. As can be seen, there was a positive and significant relationship between exogenous variables (organizational silence and organizational voice) and endogenous variables (ethical leadership and employee performance).

The highest significant correlation was found between organizational silence and ethical leadership $(r=0.71)$, and the least significant correlation was related to organizational silence organizational voice $(r=0.37)$. Hence, any improvement in organizational silence and organizational voice will improve ethical leadership and employee performance.

Table 1. Normality test results

\begin{tabular}{ccccc}
\hline Data & Skewness & Std. Error of Skewness & Kurtosis & Std. Error of Kurtosis \\
\hline Organizational silence & 0.15 & 0.12 & 0.00 & 0.24 \\
\hline Organizational voice & 0.49 & 0.12 & 0.06 & 0.24 \\
Ethical leadership & 0.20 & 0.12 & 0.03 & 0.24 \\
\hline Employees' performance & 0.19 & 0.12 & 0.01 & 0.24 \\
\hline & & & $\begin{array}{c}\text { Hitealth in } \\
\text { Emergencies and Dlisasters (Oluarterly }\end{array}$
\end{tabular}

Table 2. The Pearson correlation test results

\begin{tabular}{|c|c|c|c|c|}
\hline Variables & Organizational Silence & Organizational Voice & Ethical Leadership & Employees' Performance \\
\hline Organizational silence & 1 & - & - & \\
\hline Organizational voice & $0.37^{*}$ & 1 & - & \\
\hline Ethical leadership & $0.71^{*}$ & $0.62^{*}$ & 1 & \\
\hline Employee performance & $0.87 *$ & $0.57 *$ & $0.7 *$ & 1 \\
\hline
\end{tabular}


Table 3. Reliability tests results

\begin{tabular}{ccccc}
\hline Variables & Cronbach Alpha & Spearman Rho & CA & Communalities \\
\hline Employee performance & 0.76 & 0.82 & 0.80 & 0.54 \\
\hline Organizational silence & 0.87 & 0.89 & 0.92 & 0.79 \\
\hline Organizational voice & 0.86 & 0.86 & 0.91 & 0.78 \\
Ethical leadership & 0.79 & 0.80 & 0.86 & 0.61 \\
\hline & & & $\begin{array}{c}\text { IHealth in } \\
\text { Emergencies and [D]isasters [Oluarterly }\end{array}$
\end{tabular}

Table 4. Discriminant validity test by the cross-loadings method

\begin{tabular}{|c|c|c|c|c|}
\hline Components & Employee Performance & Organizational Silence & Organizational Voice & Ethical Leadership \\
\hline AQ1 & 0.22 & 0.83 & 0.18 & 0.11 \\
\hline AQ2 & 0.33 & 0.92 & 0.28 & 0.09 \\
\hline AQ3 & 0.29 & 0.90 & 0.21 & 0.14 \\
\hline BQ1 & 0.45 & 0.23 & 0.89 & 0.19 \\
\hline BQ2 & 0.48 & 0.27 & 0.92 & 0.19 \\
\hline BQ3 & 0.44 & 0.18 & 0.84 & 0.31 \\
\hline CQ1 & 0.35 & 0.11 & 0.19 & 0.77 \\
\hline $\mathrm{CQ} 2$ & 0.28 & 0.13 & 0.22 & 0.80 \\
\hline $\mathrm{CQ3}$ & 0.41 & 0.07 & 0.25 & 0.79 \\
\hline $\mathrm{CQ} 4$ & 0.30 & 0.09 & 0.14 & 0.75 \\
\hline DQ1 & 0.88 & 0.30 & 0.45 & 0.40 \\
\hline DQ2 & 0.83 & 0.21 & 0.47 & 0.34 \\
\hline DQ3 & 0.77 & 0.28 & 0.33 & 0.33 \\
\hline DQ4 & 0.74 & 0.24 & 0.38 & 0.34 \\
\hline DQ5 & 0.79 & 0.09 & 0.23 & 0.13 \\
\hline
\end{tabular}

$\mathrm{AQ}=$ Employ Silence, $\mathrm{BQ}=$ Employ Voice, $\mathrm{CQ}=$ Ethical Leadership, $\mathrm{DQ}=$ Employ Performance

Table 5. Discriminant validity test by Fornell-Larcker criterion

\begin{tabular}{|c|c|c|c|c|}
\hline Variables & Employees' Performance & Organizational Silence & Organizational Voice & Ethical Leadership \\
\hline Employee performance & 0.73 & & & \\
\hline Organizational silence & 0.32 & 0.89 & & \\
\hline Organizational voice & 0.52 & 0.26 & 0.88 & \\
\hline Ethical leadership & 0.44 & 0.13 & 0.26 & 0.78 \\
\hline
\end{tabular}




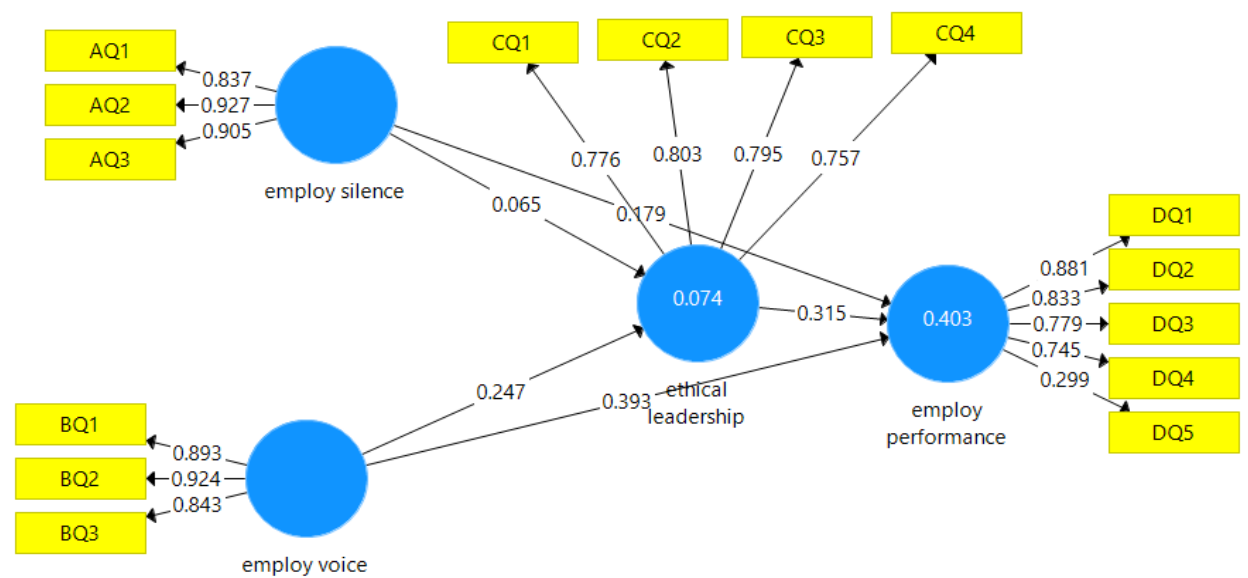

Figure 1. The structural model with path coefficients

Health in

Emergencies and |D]isasters [Q]uarterly

Testing the reliability of the measurement model

The reliability of the measurement model was tested by measuring the Cronbach alpha, Composite Reliability (CR), Spearman correlation coefficient (Rho), and Communality Reliability (CR). The results showed that all variables had a Cronbach alpha value of more than 0.7 . According to Henseler et al. (2009), the model is reliable, if CR $>0.7$. Moreover, according to Ringer (2016), Spearman Rho $>0.7$ and communality $>0.5$ indicate the good reliability of the model. Based on the results of these four tests, the model is reliable (Table 3 ).

Testing the validity of the measurement model

For testing the discriminant validity of the measurement model, cross-loadings and Fornell-Larcker tests were performed. According to the cross-loadings test, each question accurately measures its own variables and does not correlate with the other set of questions. Table 4 presents the results for the cross-loadings test. Since the values obtained for each variable are at least 0.1 higher than those of other variables, the discriminant validity of the model was confirmed by the cross-loadings method. the Fornell-Larcker criterion. According to this method, the numbers that occupy the row and column should be higher than the numbers in other rows and columns. According to the obtained data, the discriminant validity of the measurement model was confirmed (Table 5).

The structural path analysis results are presented in Table 6. Using the following formula, the coefficient of determination $\left(\mathrm{R}^{2}\right)$ and the Goodness-of-Fitness (GOF) index for the study model were obtained as $=0.64$ and 0.209 , respectively, which indicated its good fit.

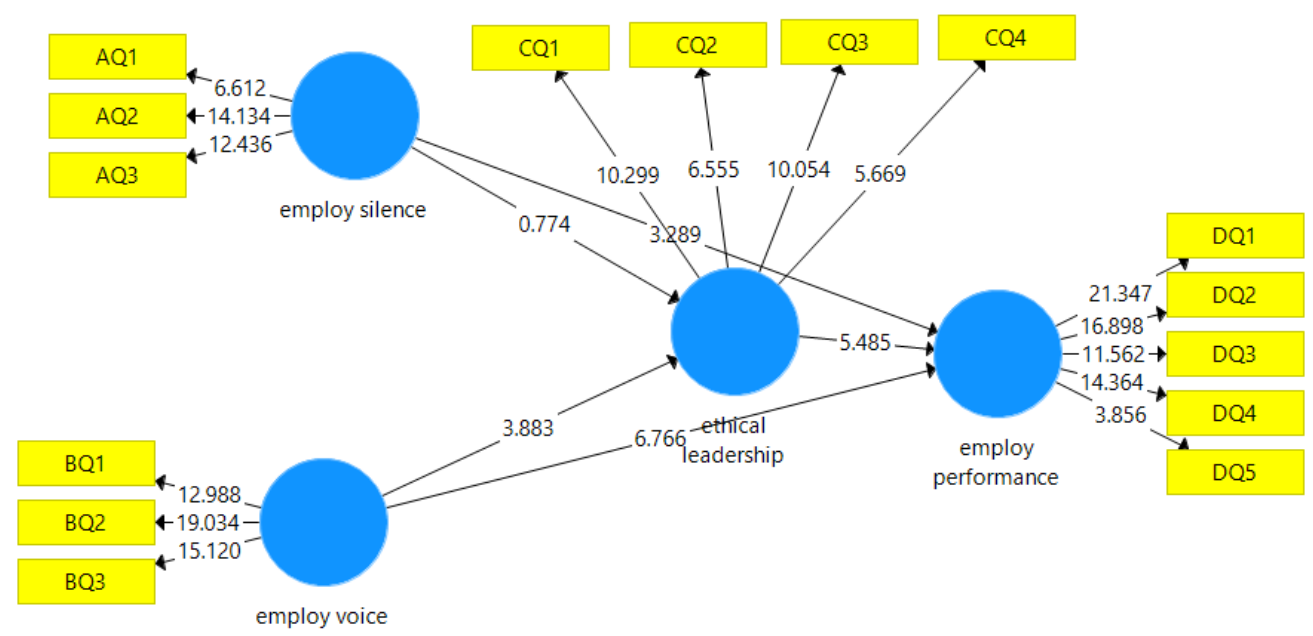

Figure 2. The structural model with significant values 
Table 6. Structural path analysis results

\begin{tabular}{ccccc}
\hline Relationship & Path Beta & t Values & Decision & GOF \\
\hline EP-OS & 0.17 & 3.28 & Supported \\
EP-OV & 0.39 & 6.76 & Supported \\
EL-OS & 0.06 & 0.77 & Rejected & 0.209 \\
EL-OV & 0.24 & 3.88 & Supported \\
OS/OV-EL-EP & 0.31 & 5.48 & Supported \\
\hline
\end{tabular}

EP: Employee Performance; OS: Organizational Silence; OV: Organizational Voice; EL: Ethical Leadership; GOF: the Goodness Of Fitness index

\section{Discussion}

The effect of organizational noise and silence on organizational performance has recently become one of the fundamental organizational challenges. In this study, the SEM model was designed to investigate variables related to staff performance, based on the literature review. In this structural model, variables of organizational silence and employees' voice were considered as contextual factors that explain ethical leadership through mediation. The results also indicated that the model was valid regarding the study population and could explain the final endogenous variable.

The first hypothesis related to the association between organizational silence and employees' performance with a path coefficient of 0.39 and a significant level of 3.28 was confirmed at a 99\% confidence interval. Employees, as important organizational resources, often have useful information and ideas to improve their works and organizations, which sometimes express them. However, sometimes they remain silent, and this silence can affect their performance.

Employees play a crucial role in organizations with important implications for their organizations and other individuals working there. They also can overshadow the performance of the organizations. If employees do not share their ideas and concerns, the organization will not be able to identify and correct problems or take advantage of new ideas. Regarding the staff working in the fire station, the desire to speak to managers can improve the organizational image and performance. This result is consistent with the findings of other studies $[8,10]$.

The second hypothesis related to the relationship between organizational voice and employee performance, with a path coefficient of 0.17 and a significant level of
6.76, was confirmed at a $99 \%$ confidence interval. Managers and leaders in fire stations and other health and safety organizations must provide the employees with the climate and conditions to voluntarily express their opinions, concerns, and information about issues and problems in the organization, by which they can contribute to the organization's performance and efficiency. The result agrees with other studies [11].

The third hypothesis about the relationship between organizational silence and ethical leadership, with a path coefficient of 0.06 and a significant level of 0.77 , was rejected at a $99 \%$ confidence interval. As employee silence increases, the functional components of ethical leadership will not be necessarily increased.

The fourth hypothesis regarding the relationship between organizational voice and ethical leadership, with a path coefficient of 0.24 and a significant level of 3.88 , was confirmed at a $99 \%$ confidence interval. This finding is consistent with the results of other studies [5] that leadership behavior is consistently related to the employee voice, and the psychological safety of employees for having open communication with management, as a mediator, has a significant effect on their performance.

Considering the recently raised issues and identifying silence and its negative effects on organizations, and also the critical effects of organizational voice vs. organizational silence, managers should consider these common phenomena more carefully and evaluate and improve their organizations in needed situations.

Finally, the results of this study revealed that organizational voice and silence influence employees' performance through the mediating role of ethical leadership. In other words, there is a statistically significant relation- 
ship between employee voice and silence through ethical leadership and performance.

Most scholars in social sciences and organizational management have criticized the silence concerning different perceptions and approaches and pointed to its positive and negative consequences. According to similar studies [9], employee voice or silence can significantly influence the performance of those working in the fire and security services, especially when many factors make employees silent or unwilling to express their views. Hence, leaders and managers of organizations should provide the conditions for motivating employees and increasing the voice of employees. The results of this study are similar to those in the area of the relationship between ethical leadership and organizational performance [10].

One of the limitations of this study was its correlational design. Therefore, the obtained relationships cannot be interpreted causally. Moreover, we used questionnaires for collecting data. Since the questionnaires were completed by the self-report method, there may be bias in the responses. The mental state of the samples, while answering questions, could also affect the outcome by presenting incomplete and inaccurate information. Therefore, the accuracy of responses cannot be guaranteed. It is suggested that in future studies, interviews and observation be used to gather information.

\section{Conclusion}

Nowadays, employees' silence and voice and finding ways to avoid silence are of great importance in organizations, including service organizations. As the findings of the present study showed, the silence of employees working in the fire and safety departments can reduce their performance. When the climate of silence prevails at the fire stations, the views and opinions of the staff will not have the opportunity to be expressed. Organizational silence is a common phenomenon there, which can be perceived by managers and employees.

It should be noted that different incentives of firefighting staff lead to a particular type of organizational silence or voice and as a result, employees deliberately refuse to provide information, opinions, and ideas and cause a form of silence or voice that will have irreparable consequences due to their essential role in helping and saving lives. As the third-millennium organizations struggle to survive in a dynamic environment filled with diverse cultural, political, economic, and social challenges, they need staff who are compassionate in their efforts to preserve the organization.

These organizations do not want silent staff because of their indifference or fear of endangering their interests, because under such circumstances, the quality of decision-making decreases. Without feedback, corrective actions will not take place in time and errors will increase. Therefore one of the most important tasks of the managers and leaders of the fire and security departments is to identify and break the organizational climate of silence to ensure the organization's survival and growth.

\section{Ethical Considerations}

\section{Compliance with ethical guidelines}

This study obtained ethical approval due to observing the ethical guidelines of Payame Noor University. The research objectives and methods were explained to the participants and they were assured of the confidentiality of their information. They were free to leave the study at any time. Also, the results were provided for those who were willing to be informed about the findings of the research.

\section{Funding}

The study had no financial backing or sponsorship.

\section{Authors' contributions}

Data analysis: Matineh Moghaddam; Editing and Reviewing: Tohid Alizadeh Hossein Hajlou, Reza Norouzi Ajirloo.

\section{Conflict of interest}

The authors declared no conflict of interest was reported.

\section{Acknowledgments}

The authors would like to thank all who participated or cooperated in conducting this study.

\section{References}

[1] Afkhami Ardakani M, Khalili Sadr Abad O. The Relationship between personality factors and silence of knowledge employees. Journal of Public Management Researches. 2016; 18: $65-84$.

[2] Elizabeth W, Morrison F, Milliken J. Organizational silence: A barrier to change and development in a pluralistic world 
The Academy of Management Review. 2003; 25(4) :706-25. [DOI:10.5465/amr.2000.3707697]

[3] Zare'i Matin H, Taheri F. Organizational silence: Concepts, causes and consequences. Journal of Management Science of Iran. 2012; 6(21):77-104.

[4] Morrison E, Milliken F. Organizational silence: A barrier to change and development in a pluralistic world. Academy of Management Review. 2015; 25(4):201-25. [DOI:10.2307/259200]

[5] Pinder CC, Harlos KP. Employee silence: Quiescence and aquiescence as response to percieved injustice. In: Ferris GR, Editors, Research in Personnel and Human Resources. Bingley: Emerald Group Publishing; 2001.

[6] Rostami, Honest Believer; Feizi ,S, J; Piri ,M and Tasouji, Kh. Study of the relationship between the quality of working life and burnout among employees of the Tax Administration of the West Azerbaijan province. Paper Peresented at: The $1^{\text {st }}$ National Conference on Accounting and Management. 16 September 2013; Noor Branch, Islamic Azad University, Noor, Iran.

[7] Zarei Matin H, Taheri F, Seyyed A. Organizational silence: Concepts, causes, and consequences. Iranian Journal of Management Science. 1390; 6(21):77-104.

[8] Acaray A, Abdülkadir A. The relationship between organizational citizenship behavior and organizational silence. Journal of Social and Behavioral Sciences. 2015; 207(2015):472-82. [DOI:10.1016/j.sbspro.2015.10.117]

[9] Van Dyne L, Ang S, Botero IC. Conceptualizing employee silence and employee voice as multidimensional construct. Journal of Management Studies. 2003; 40(2):1359-2014. [DOI:10.1111/1467-6486.00384]

[10] Amani M, Moravoty Sharif Abadi A, Mirzai Ali Abadi $\mathrm{M}$. Investigating the relationship between organizational silence and organizational agility from the viewpoint of higher education staff. Organizational Culture Management. 2015; 15(2):465-82.

[11] Brown ME, Trevin'o LK, Harrison D. Ethical leadership: A social learning perspective for construct development and testing. Organizational Behavior and Human Decision Processes. 2005; 97(2):117-34. [DOI:10.1016/j.obhdp.2005.03.002]

[12] Fatima A, Salah-UD-Din S, Khan S, Hasan S, Hoti H. Impact of organizational silence on organizational citizenship behavior: Moderating role of procedural justice. Journal of Economics, Business, and Management. 2015; 3(9):846-50. [DOI:10.7763/JOEBM.2015.V3.296]

[13] Xiaotwao Z, Jianglin K, Jintao S. Survey on employee silence and the impact of trust in China. Acta Psychologica Sinica Beijin. 2008; 40(2):219-27. [DOI:10.3724/SP.J.1041.2008.00219]

[14] De Hoogh AH, Den Hartog DN. Ethical and despotic leadership, relationships with leader's social responsibility, top management team effectiveness and subordinates' optimism: A multi-method study. The Leadership Quarterly. 2008; 19(3):297-311.[DOI:10.1016/j.leaqua.2008.03.002]

[15] Fuentes-Fuentes MM, Albacete-Sáez CA, Lloréns-Montes FJ. The impact of environmental characteristics on TQM principles and organizational performance. Omega. 2004; 32(6):425-42.
[16] Shojaie S, Zaree Matin H, Barani Gh. Analyzing the infrastructures of organizational silence and ways to get rid of it. Social and Behavioral Sciences. 2011; 18(30):389-96 [DOI:10.1016/j.sbspro.2011.10.334]

[17] Van Dyne L, Lepine JA. Helping and voice extra-role behaviors: Evidence of construct and predictive validity. Academy Of Management Journal. 1998; 41:108-119. [DOI:10.2307/256902]

[18] Ullah S, Ullah A, Durrani B. Effect of leadership on employees performance in multinational pharmaceutical companies in Pakistan, interdisciplinary. Journal of Contemporary Research In Business. 2011; 2(9):286-99. 